\title{
RESEARCH
}

Open Access

\section{Post-Western sociologies: what and why?}

\author{
Lizhong Xie(1)
}

Correspondence: Lzxbjdx@sina.com This paper is translated by Tu Peng and Tang Kai from Chinese. Thanks to two anonymous reviewers for their valuable suggestions for revisions to this article. The author is responsible for the remaining issues in this article. Sociology Department, Peking University, Beijing, China

\begin{abstract}
"Post-Western sociologies" mainly refer to some sociological systems constructed by non-Western and Western sociologists, after the so-called "Western sociologies" have been spread to the non-Western world. It includes various types, such as "nonwesternized Western sociologies," "westernized non-Western sociologies," and "nonWestern sociologies." "Post-Western sociologies" therefore are neither equal to "nonWestern sociologies" nor equal to "de-westernized" or "anti-westernized" sociologies. Compared with concepts such as "de-Westernization" or even "indigenization," the concept of "post-Westernization" is more inclusive.
\end{abstract}

Keywords: Western sociologies, Post-Western sociologies, Non-Western sociologies, De-Westernization, Post-Westernization

In recent years, some French and Chinese sociologists have cooperatively carried out a research project named "Post-Western sociologies." Starting with both theoretical and empirical studies, they try to construct a sociological knowledge system beyond the dualism of Western and non-Western systems. Scholars have promoted a large quantity of work around the main theme. However, the essential question of this project, which is a theoretical one, i.e., "What are post-Western sociologies," has been more or less neglected, except the work from Professor Roulleau-Berger (2011, 2015, 2016), the governor of this project in France. From my standpoint, it has an adverse impact on the project. As one of the scholars who invented and proposed the concept of "PostWestern sociologies," I will try to give a brief response to this essential question, state my understanding of the connotation and meaning of this concept, and expect to consult with domestic and overseas colleagues.

The question "What are post-Western sociologies" will be discussed based on the following perspectives.

\section{What are "post-Western sociologies?" What are "post-Western sociologies"?}

What concerns me is that, when seeing the phrase "post-Western sociologies," people will (or should) envisage "non-Western," "de-Western," even "anti-Western" sociologies. In my opinion, it is not appropriate to understand "post-Western sociologies" as a "non-Western," “de-Western," even "anti-Western" sociologies. "Post-Western

(c) The Author(s). 2021 Open Access This article is licensed under a Creative Commons Attribution 4.0 International License, which permits use, sharing, adaptation, distribution and reproduction in any medium or format, as long as you give appropriate credit to the original author(s) and the source, provide a link to the Creative Commons licence, and indicate if changes were made. The images or other third party material in this article are included in the article's Creative Commons licence, unless indicated otherwise in a credit line to the material. If material is not included in the article's Creative Commons licence and your intended use is not permitted by statutory regulation or exceeds the permitted use, you will need to obtain permission directly from the copyright holder. To view a copy of this licence, visit http://creativecommons.org/licenses/by/4.0/. 
sociologies" includes those sociological systems that are "non-Western," "de-Western," or "anti-Western" but are not equal to or limited to these types of sociology.

Just as the name implies, "post-Western sociologies" are the sociologies formed and developed in the "post" era of the so-called "Western sociologies." In my paper Post-Sociologies, according to my explanation of this word, the prefix "post-" means that, first, even though it is not completely opposite to what makes it "post," it is still quite different; second, although it is quite different from what makes it "post," its ultimate form is still not completed and hence difficult to define. Therefore, we cannot give it a fixed name, but vaguely name it as "post-xx" instead, for instance, "post-structuralism," "post-modernism," "post-industry society," "post-modern society," "post-capitalism," and "post-planned economy." Similarly, "post-Western sociologies" mean that, first, they are quite different from what we called "Western sociologies;" second, their forms are not yet completed and fixed. Therefore, they have to be understood by the difference from the things that make them "post"- "Western sociologies" (Xie 2012:1-2). Moreover, this also means that, similar to what we do when we understand the word "post-sociologies," in order to understand the true meaning of "post-Western sociologies," we need to understand the things that makes them "post," which are "Western sociologies."

\section{What are "Western sociologies," then?}

Technically, "Western sociologies" is a concept without an accurate definition. However, what can be certain is that the word "Western" does not refer to a pure geographic concept (because nothing can be "post" of the geographic "Western"), but a spatial concept with cultural meanings. It is a typological concept. As a Weberian ideal type, "Western sociologies" can be generally defined as such: they refer to those sociological systems that are constructed and developed by Western sociologists, take the social life experience of Western people as material, are under the guidance and constraints of traditional Western discourse systems, and initially expressed in a Western language.

The definition of "Western sociologies" here concludes the following basic factors:

First, "Western sociologies" were constructed by the sociologists who worked and lived in Western countries and to some extent, were theoretically abstracted by them through the life experience and historical memory in their own societies.

Second, "Western sociologies" were constructed by the sociologists who worked and lived in Western countries, solely or mainly under the guidance and within the restriction of the traditional Western discourse system (such as the discourse system of ancient Greece-Rome, of Christianity, of modern Enlightenment or anti-Enlightenment) ${ }^{1}$.

Third, with the exception that "Western sociologies" were constructed by Western sociologists, solely or mainly under the guidance and within the restriction of the traditional Western discourse system, they were initially expressed in Western language, treating Western audiences as the initial listening object.

A social theory can be categorized into "Western sociologies," only if it has the three factors above at the same time. If (1) a sociologist, who works and lives in the "West,"

\footnotetext{
${ }^{1}$ There are numerous debates about the features of the traditional Western discourse system; however, due to the limited length of the paper, this issue will not be discussed here.
} 
is unwilling to construct his/her social theory under the guidance and within the restriction of the traditional Western discourse system, but consciously or unconsciously constructs his/her social theory according to some traditional non-Western discourse system, such as the discourse system (concept, statement and clue) of Chinese Confucianism (or Buddhism, Taoism); or (2) a sociologist, who works and lives in the "West," is willing to construct his/her social theory under the guidance and within the restriction of the traditional Western discourse system, but first expresses it in non-Western language (such as Chinese). Therefore, his/her theory (almost) never treats Western audiences as the object, or (almost) never has any impact on the field of Western sociology; or (3) a non-Western sociologist is willing to construct his/her social theory under the guidance and within the restriction of the traditional Western discourse system and initially expresses it mostly in Western language, but he/she has never or seldom worked or lived in Western countries, without any concrete experience of Western social life or academic atmosphere.

The social theories constructed by these sociologists above are not in the list of "Western sociologies" mentioned here. Although the three assumptions above are not quite common in actual Western society so far, they still might exist theoretically. Hence, "Western sociologies" mentioned here should be distinguished from "sociologies that exist in Western countries." The former does not include the three assumptions above, while the latter does.

Additionally, one more concept that should be clarified is that the word "Western sociologies" refers to the plural form (sociologies) instead of the singular form (sociology); there is no single "Western sociology" generally recognized. Just as Ritzer stated, Western "sociology" is a multiparadigm discipline.

Therefore, "post-Western sociologies" refer to a new kind of sociology that is formed and developed after these "Western sociologies" defined above, on the basis of cultural interaction between Western and non-Western sociologists. According to the three basic factors about "Western sociologies" above, the basic factors of "post-Western sociologies," in the broadest sense, could be described as follows:

First, "Western sociologies" are constructed not only by sociologists working and living in Western countries but also by both Western and non-Western sociologists together, and they are theoretically abstracted by sociologists from various countries through the social life experience and historical memory of both their own and shared aspects. Compared with the "Western sociologies" defined above, they have more sources of discourse subjects, life experience, and historical memory.

Second, "post-Western sociologies" are not constructed under the guidance and within the restriction of the traditional Western discourse system but are constructed by both Western and non-Western sociologists under the guidance and within the restriction of both Western and non-Western discourse systems. Therefore, compared with the "Western sociologies," they have more discourse sources.

Third, "post-Western sociologies" are not initially expressed in Western language, but in various languages including both Western and non-Western languages. Therefore, compared with the "Western sociologies," they have more language carriers and more types of audiences.

The criterion of "post-Western sociologies" is quite different from that of the "Western sociologies." In the broadest sense, to be a member of "post-Western sociologies," a 
social theory does not have to own all of the three factors above at the same time but has to own only one of the three. Specifically, as follows:

1. A social theory can be categorized into "post-Western sociologies," as long as it is not constructed under the guidance and within the restriction of the traditional Western discourse system. This applies regardless of whether it is constructed by sociologists living and working in Western or non-Western countries and whether it is initially expressed in Western or non-Western language.

2. A social theory can be categorized into "post-Western sociologies," as long as it is constructed by sociologists living and working in non-Western countries. This applies regardless of whether it is initially expressed in Western or non-Western language and whether it is constructed under the guidance and within the restriction of the traditional Western discourse system or not.

3. A social theory can be categorized into "post-Western sociologies," as long as it is initially expressed in non-Western language or in Western and non-Western language together. This applies regardless of whether it is constructed by sociologists living and working in Western or non-Western countries and whether it is constructed under the guidance and within the restriction of the traditional Western discourse system or not.

The reason is simple. As previously mentioned, a social theory can be defined as a member of "Western sociologies," only if it has the three basic factors at the same time-proposed by Western sociologist, constructed under the guidance and within the restriction of the traditional Western discourse system, and initially expressed in a Western language. If one of the basic factors is missing (it is not proposed by Western sociologists, or not constructed under the guidance and within the restriction of the traditional Western discourse system, or not initially expressed in a Western language), it can be defined as "post-Western sociologies."

However, this description might still be ambiguous and vague for understanding. To offer a more concrete and explicit understanding of "post-Western sociologies," more detailed discussion must be made.

\section{"Post-Western sociologies" in non-Western countries}

The "post-Western sociologies" formed and developed in the wake of the "Western sociologies" include two parts: one is the sociologies formed and developed in nonWestern countries; the other is the sociologies consecutively developed in Western countries. A more detailed investigation on the sociologies in these two kinds of countries could be made. First, it is the sociologies formed and developed in non-Western countries.

Generally, non-Western "sociologies," formed and developed in the wake of "Western sociologies," are the results of the transmission of "Western sociologies" to nonWestern countries. Therefore, they all seemingly could be categorized into "post-Western sociologies." However, the truth is that this is not the case. If some theories of Western sociologies transmitted to certain non-Western countries are simply translated in the level of expressive language (translated from some Western language into some non-Western language, such as from English into Chinese) and hence there is no 
substantial change, then the theories should still be categorized into "Western sociologies," rather than the so-called "post-Western sociologies" here, although in the process of translation, the connotation and extension of these theories may be different from the connotation and extension in the original mother language. At most, these translated theories could be named "Western sociologies translated into a certain language" (such as "Western sociologies translated into Chinese"). In fact, this is the primary form of almost all sociologies in non-Western countries ${ }^{2}$.

Then, could "post-Western sociologies" be connected with the sociological indigenization in non-Western countries and the sociological theories indigenized in non-Western countries be categorized into "post-Western sociologies?" In my opinion, the answer is still no. For illustration, about the result of "indigenization" of sociologies or social science in non-Western countries, a more detailed analysis could be made.

Through deliberative analysis, it is clear that the "indigenization" of sociologies or social science in non-Western countries can be categorized into the following types.

The first type is the indigenization of research objects, which means the research objects mainly aimed at Western societies have been transformed into those mainly (or even only) aimed at non-Western societies. Meanwhile, in other aspects (such as basic concepts, theoretical propositions, research methods, etc.), the indigenization has not yet happened. Some concepts from Chinese sociologists could be used to describe this type as "object-transformed indigenization." It was the initial expectation for sociologists from non-Western countries in the process of sociological "indigenization" and the primary form of "indigenized sociologies" in non-Western countries. For instance, at the time of formation of Chinese sociologies in the early twentieth century, the expectation of sociological "indigenization" initiated by Xu Shilian, Sun Benwen, Wu Wenzao, Li Jinghan, etc. was that the concepts, propositions, and theories from Western societies could be connected with empirical materials from Chinese society.

The second type is the indigenization of both research objects and some other aspects, to some extent, such as basic concepts, theoretical propositions, and research methods. For instance, some concepts, propositions, and methods originally from the West were modified and transformed based on the indigenous context (distinguishing “jiating (家庭)," “jiazu (家族)," and “zongzu (宗族)” from the concept of “family"; distinguishing "shequ (社区)" and "shequn (社群)" from the concept of "community"; integrating "nation" and "ethnic" into the concept of "nation (minzu民族)"; some new concepts, such as “chaxugeju (差序格局)” and “danwei (单位),” propositions and methods were created based on the indigenous discourse resource; and some new theoretical systems, originally from the West but different, were constructed by reinterpretation and reconstruction of the given Western theoretical systems (for example, construction of a Chinese neo-functionalism by integrating English socioanthropological functionalism and the Chicago School of urban ecology). Therefore, the social theories adopted by the native scholars from the West have been more or less supplemented, modified, and renewed, and this type could be named as "supplemented-modified-renewed indigenization." Theoretically, due to the differences of

\footnotetext{
${ }^{2}$ It also indicates that similar to "Western sociologies" that cannot be compared to "sociologies in Western countries," "post-Western sociologies" cannot be compared to "sociologies in non-Western sociologies." "Post-Western Sociologies" does not include "Western sociologies," while "sociologies in non-Western sociologies" could include "Western sociologies" or "Western sociologies translated into a certain language."
} 
cultural tradition, historical experience, natural environment, and structure between nonWestern and Western countries and the variation in understanding and use of concepts and propositions caused by sociologists, the indigenization of research objects will lead to the indigenization of theoretical concepts and propositions. Most of the results of nonWestern sociologies could be categorized into this category. For instance, Fei Xiaotong, based on the research on Chinese rural areas, supplemented and modified Malinowski and Brown's functionalist anthropology and developed a sociological-anthropological theory, which became the model of "supplemented-modified" indigenized sociologicalanthropological theory. Since sociology was rebuilt in China, the contemporary Chinese sociologists have consciously constructed numerous indigenized sociological theories with "Chinese characteristics," such as "structural sociology" proposed by Lu Xueyi, "social structure transition" theory by Li Peilin, "structural-institutional analysis" by Li Lulu, Li Qiang, Li Hanlin and Zhangjing, "process-event analysis" by Sun Liping, "school of social operation" or "social mutual-constructionism" by Zheng Hangsheng, sociology of "phenomenology in daily life" by Yang Shanhua, "pluralistic discourse analysis" by me, "emotional choice theory" by Liu Shaojie, "sociological Marxism" by Shen Yuan, "space-time sociology" by Jing Tiankui, and "social biology" by Zheng Yefu.

The third type is not only the indigenization of research objects but also the radical and thorough indigenization of theories (concepts and propositions), which means that the Western concepts or propositions are fully or mainly abandoned and a set of indigenized concepts and propositions originating from the native people's social life are adopted instead; however, the thinking patterns and research methods still follow those from Western sociologies (such as positive scientific method, hermeneutics, dialectical method, and so on, especially the positive scientific method). Quoting the words from some Chinese scholars, it means using Western modern scientific methods to study the social and cultural contents in indigenous China (Yang 2012). This type could be named as "theoretical substitution indigenization." For instance, the indigenization movement in the field of sociology/social psychology, initiated by Yang Guoshu, Huang Guangguo and Yang Zhongfang in Taiwan and Hong Kong and continued by some scholars in Chinese mainland such as Zhai Xuewei, to some extent was the attempt to use Western modern scientific methods (mainly the positive scientific methods, such as the questionnaire survey and experiment) to study Chinese society, culture and behavior and to use some concepts (such as "renqing (人情)," “mianzi (面子)," “yuanfen (缘分),” “guanxi (关系),” “mingfen (名分)," “qi (气),” and“danwei (单位)”) and propositions (such as "when the six layers of 'qichang (气场)' are completed, the mass disturbance is inevitable") (Ying 2011:195) originating from Chinese society, culture and psychological life to explain Chinese society, culture and behavior.

The fourth type makes a further step on the basis of the third type. It attempts to make radical and thorough indigenization not only of research objects and theories (concepts and propositions) but also of thinking patterns and research methods, which means the thinking patterns and research methods from Western social science have been substituted by non-Western (Chinese) and traditional ones ${ }^{3}$, and meanwhile fully indigenized sociological theories (for instance, Confucianist sociology, Buddhist

\footnotetext{
3"What are the Chinese traditional thinking patterns and research methods?" The debates and controversies on this question never stopped since the Western theories have been introduced. However, there seems to be a common view that a vast or even fundamental difference between the Chinese thinking patterns and the Western patterns exists.
} 
sociology, Taoist sociology, and Islamic sociology) have been created in three aspectsresearch objects, theories (concepts and propositions), and research methods, where "the Western" has been completely substituted by "the indigenous." This type could be named as "theoretical-methodical substitution indigenization." Recently, a school of scholars self-proclaimed as "neo-Confucianism in mainland" emerged in China mainland; they claimed a neo-Confucianism and its doctrines with a strong meaning of indigenization, including a set of highly indigenized "neo-Confucianist social theories." If it can be systematically illustrated, its results, to a large extent, can hence be categorized into the type of "theoretical-methodical substitution indigenization." As a matter of fact, the "qunxue (群学)" explained by Kang Youwei, Liang Qichao, and Yan Fu who was inspired by Western sociologies, in the late nineteenth century and the early twentieth century, were quite similar to the theories of "theoretical-methodical substitution indigenization" mentioned here. It is the reason why the scholars of "neo-Confucianism in mainland" appealed to "returning to Kang Youwei" in recent years.

Due to the following reasons, the last type of "indigenized" sociological theories can also be described as "non-Western sociologies." According to the definition of "Western sociologies" above, "non-Western sociologies" can be defined as sociological theories with the following features.

1. Merely constructed by sociologists in non-Western countries or regions

2. Merely constructed under the guidance and within the restriction of the traditional non-Western discourse system

3. Merely initially expressed in the non-Western language

The last type of non-Western indigenized sociologies is exactly the type of sociological theory that is constructed by non-Western sociologists under the guidance and within the restriction of the traditional non-Western discourse system and initially expressed in non-Western language. Therefore, it is fully justifiable to name these types as "non-Western sociologies."

Certainly, it is necessary to clarify that "non-Western sociologies" does not commonly exist as a whole. As the results of a radical or thorough "indigenization" movement, "non-Western sociologies" are usually segmented into some theoretical systems applied in narrower spaces, such as "Chinese sociologies," "Eastern Asian sociologies," "Latino sociologies," "Brazilian sociologies" and so on. Some more specific schools can even be distinguished according to the theoretical features, for instance, "Chinese sociologies" could be furtherly divided into "Confucianist sociology," "Buddhist sociology," "Taoist sociology," "Legalists sociologies," etc. The four types above belong to Weber's "ideal type" because the indigenized theories in real life cannot be so distinguishable as they are described here; instead, they might be in a state with blurred boundaries. However, the four ideal types can still be used to understand and discuss the relevant issues.

In regard to the second and third type of "indigenized sociologies" in non-Western countries, it is clear that they cannot be categorized into neither "non-Western sociologies" nor "Western sociologies." First, they are different from "Western sociologies" in the aspects of research subjects, theoretical systems (concepts, propositions, etc.), and initiative languages. The most important difference is in theoretical systems. Even "supplemented-modified-renewed indigenization" sociologies (in addition to "theoretical 
substitution indigenization") are hardly equal to Western sociologies that need to be supplemented and modified by it. For instance, although most of the sociological theories in China's mainland belong to the type of "supplemented-modified-renewed indigenization," no one would ever consider them as "Western sociologies." Numerous Western concepts (such as structure, construction, mutual-construction, system, mechanism, function, family, organization, community, class, nation, evolution, and progress) and propositions are adopted, but the connotation of many concepts (such as family, community, class, and nation) has already changed. If these changes are neglected or lack awareness, many works in the sociological literature of contemporary China cannot be fully understood. Second, these sociological theories are crucially or even fundamentally different from "non-Western sociologies," and hence cannot be categorized into them. For instance, although the theories of "supplemented-modified-renewed indigenization" are quite different from their maternal Western theories and they cannot be mixed together, they are still closely linked to each other. Many concepts and propositions, whose connotation (content) and extension (range of application) are still different from those of maternal Western theories, might be developed from the latter. Because of their close relationship, the former cannot be identified as "non-Western sociologies;" although in terms of basic concepts and propositions, the link between the theories of "theoretical substitution indigenization" and Western sociologies has been cut off, the thinking patterns and research methods of the former are still Western (and might be supplemented and modified to some degree according to non-Western societies). Hence, to a large extent, they are still highly westernized, rather than "nonwesternized". This is analogous to Chinese medicine that has been transformed based on Western modern science and thus cannot be identified as pure "Chinese medicine," but as a westernized one. In a certain sense, however, the theories of "supplementedmodified-renewed indigenization" can be considered as "non-westernized (such as Chinese) Western sociologies," and theories of "theoretical substitution indigenization" as "westernized non-Western sociologies" (such as "westernized Chinese sociologies" or "westernized Confucianist sociologies"). Nevertheless, they cannot be equal to the fourth type of indigenized theories named as "non-Western sociologies."

Then, what is the relationship between the four types of indigenized sociological theories in non-Western countries above and "post-Western sociologies"? Can they all be categorized into "post-Western sociologies?" The answer is no.

I consider, strictly speaking, that the theories of the first type "object-transformed indigenization" should be categorized into "Western sociologies" rather than "nonWestern sociologies." The reason is simple, in that they only supplement Western sociologies with some empirical materials in non-Western societies, while in terms of basic concepts, propositions and theoretical logic, and Western sociologies are not supplemented, modified, or even replaced. Hence, they are basically still the sociologies constructed by Western sociologists under the guidance and within the restriction of the traditional Western discourse system and initially expressed in Western language, and they are not different fundamentally from the so-called "Western sociologies translated into a certain language."

It is often said that the research object of Western sociologies is Western societies; hence, sociologies whose research object is not Western societies do not belong to "Western sociologies." I consider it incorrect. In truth, both Western sociologies and 
non-Western sociologies are not simply distinguished by geographical disparities, but by the three factors above (especially the second one-the traditional discourse system that guides and restricts it). As a matter of fact, even though according to the three factors above, the theories of those classic sociologists (such as Marx, Comte, Durkheim, Weber, Tönnies, and Parsons) could be categorized into "Western sociologies," their research objects were not limited to Western societies but extended to all the human societies. Although the research objects of the sociological theories constructed by nonWestern sociologists are mostly the indigenous social realities, it does not mean that only the indigenous societies rather than other societies (including Western societies) can be their research objects, which is well illustrated by the rise of "overseas ethnography" studies in China mainland during the past few years. Therefore, it is not reasonable to hold that the sociologies of "object-transformed indigenization" whose research objects are no longer Western societies should not continue to be categorized into "Western sociologies."

Therefore, on the basis of the definitions herein, among the four types of indigenized sociological theories in non-Western countries, only the last three could and should be categorized into "post-Western sociologies." In regard to sociologies in non-Western countries, a dual model of "Western sociologies and post-Western sociologies" can be offered. According to this model, in non-Western countries, "post-Western sociologies" contain (but are not equal to) "non-Western sociologies" such as "oriental sociologies," "Southern sociologies," and "Eastern Asian sociologies.". They refer to all the other sociological theories except "Western sociologies translated into a certain language" and sociologies of "object-transformed indigenization."

\section{"Post-Western sociologies" in Western countries}

Now, we turn to "post-Western sociologies" in Western countries.

After "Western sociologies" are spread to non-Western countries, they continue to exist and develop in Western countries. Meanwhile, some new changes that gradually occur might stimulate "post-Western sociologies" to form in Western countries. These changes are closely connected with the study and knowledge of Western sociologists on sociologies in non-Western countries.

With the formation and development of sociologies in non-Western countries, some Western sociologists, with a broad sphere of vision and owning the financial and linguistic conditions, chose to walk out of the West and step into non-Western countries to carry out their studies. In regard to these studies carried out by Western sociologists in non-Western countries, their results might contain the following situations:

First, through the field study, empirical materials used to testify Western sociological theories are acquired. As previously mentioned, although many Western sociologists in their lifetime make their own societies the actual research objects, almost all the worldwide influential Western sociological theorists hope their theory will be applicable to social types at all times and in all places over the world with universal validity. However, due to the limitation of space-time and research resources (for instance, finance, energy, and ability), when they construct their sociological theories, the acquired situations in their own societies are relatively more detailed and accurate than that those in other societies, especially in non-Western societies. Through the field study in nonWestern societies, the latter deficiency could be remedied. However, the results only 
testify or falsify the given theories of Western sociologists and fail to supplement or modify them in terms of basic concepts and propositions; hence, the results are similar to the theories of "object-transformed indigenization" in non-Western countries. This type of study could be named test research by Western scholars in nonWestern countries. It only exists in the primary stage of Western scholars' fieldstudying in non-Western countries. As the study proceeds further, the following results could happen.

Second, through the field study or academic communication and dialog with nonWestern sociologists who are familiar with various types of indigenized theories (including "supplemented-modified-renewed indigenization," "theoretical substitution indigenization," and "theoretical-methodical substitution indigenization"), some new concepts, propositions, and methods are acquired, and hence certain theories originating from Western sociologies are supplemented and modified (in particular, when the acquired new concepts, propositions, and methods are not only from the field study of realities in non-Western societies but also from the communication and dialog with non-Western sociologists, they would have more indigenous features of non-Western societies and more supplementation-modification-renew meanings for Western sociologies). The results are similar to the theories of "supplemented-modified-renewed indigenization" in non-Western countries. Therefore, this type of study could be named supplemented-modified-renewed research by Western scholars in non-Western countries.

Third, through the field study in non-Western societies, especially the academic communication and dialogue with non-Western sociologists who are familiar with the theories of "theoretical substitution indigenization," some new concepts, propositions, and theoretical systems are acquired that originate completely from indigenous discourse resources in non-Western societies (even constructed by nonWestern sociologists); hence, they have highly indigenous features of non-Western societies but can still be understood based on Western thinking patterns and research methods. If Western sociologists working on these types of studies are willing to accept them and adopt them to carry out various types of social studies, including Western and non-Western, then the sociological theories that are considered to be highly indigenous would turn out to be universally valid and become a part of worldwide theoretical systems including Western sociologies. If so, these types of studies could be named theoretical substitution research by Western scholars in non-Western countries.

Fourth, through field studies in non-Western societies, especially the academic communication and dialogue with non-Western sociologists who are familiar with the theories of "theoretical-methodical substitution indigenization," some new concepts, propositions, and theoretical systems are acquired that are constructed by non-Western sociologists, and hence different from the given Western sociologies in terms of theories and methods. If Western sociologists working on these types of studies are willing to accept them and adopt them to carry out various types of social studies, including Western and non-Western, then the sociological theories that are considered to be non-westernized, de-westernized, or even antiwesternized would turn out to be universally valid and become a part of worldwide theoretical systems including Western sociologies. If so, these types of studies 
could be named theoretical-methodical substitution research by Western scholars in non-Western countries ${ }^{4}$.

Therefore, as discussed above, the question is "Among all the results of sociological studies carried out by Western sociologists in non-Western countries, which of them could be categorized into the 'post-Western sociologies' mentioned here?"

In my opinion, the answer to this question is almost similar to that above. Obviously, the results of the first research type cannot be categorized into "post-Western sociologies." The reason is as simple as that above: only certain theories of "Western sociologies" are repeated and no new factors (such as new concepts, propositions, and methods) or theoretical systems are generated from it. However, the results of the last three research types can be categorized into "post-Western sociologies," because they are formed in the wake of "Western sociologies" and different from their sociological theories.

To summarize, based on the situations in Western and non-Western countries, it is clear that "post-Western sociologies" mainly refer to the sociological theories constructed by Western and non-Western sociologists after the spread of "Western sociologies" to the non-Western world. They have several types as follows:

1. Some new sociological theories are formed after Western and non-Western sociologists supplement, modify or innovate Western sociological theories, based on the context in non-Western countries or through discourse resources in non-Western countries. These theories are formed on the basis of supplementation, modification, and innovation of the given Western sociologies. The connection with each other has not been entirely cut off, but instead, they are still linked in countless ways in terms of concepts, propositions, theoretical logics, thinking patterns, and so on. They could be named "non-westernized Western sociologies" (for instance, the situation described by the Chinese phrase "Western systems adopted by China").

2. Some new sociological theories that consist of concepts and propositions of the indigenous social, cultural, and psychological life in non-Western societies are extracted by Western and non-Western sociologists, based on the research on social, cultural, and psychological life in non-Western societies and by means of Western modern scientific methods. In terms of basic concepts and propositions, the connection between these theories and Western sociological theories might have been fully cut off; hence, the former have highly indigenous features of non-Western societies. However, the fundamental idea of Western sociology has not yet been given up in that modern scientific methods are used to research societies, so these theories are still the results of processing the social and cultural contents in nonWestern countries, with Western thinking patterns as its form and instrument. Ultimately, they could be named "westernized non-Western sociologies" (for instance,

\footnotetext{
${ }^{4}$ If due to various reasons, the Western scholars who have already been in contact with theories of "theoretical substitution indigenization" and "theoretical-methodical substitution indigenization" are unwilling to fully accept them (constructed by non-Western sociologists) but are willing to absorb some discourse resources (such as concepts, propositions, and thoughts) to supplement, modify or extend the given Western sociological theories, then this type of research could only be categorized into "supplemented-modifiedrenewed research" by Western scholars in non-Western societies. The results of mixed (or hybrid) theories should also be categorized into this type.
} 
the situation described by the Chinese phrase "Chinese systems adopted by the West").

3. Some new sociological theories are formed because Western and non-Western sociologists, based on further research and an empathetic understanding of the social, cultural, and psychological life in non-Western societies, have fully given up theories and methods from Western sociologies. Meanwhile, they adopted thinking patterns and methods fully originating from non-Western societies to study both Western and non-Western societies. In terms of both research contents and research methods, these theories have features of fully non-Western culture and discourse. Because the connection with Western sociologies has been fully cut off, the characteristics of these theories are completely different from those of Western sociologies, so they could be named "non-Western sociologies."

Therefore, ultimately, regardless of whether the sociologies are those of Western countries or non-Western countries, they might contain both "Western sociologies" and "post-Western sociologies." Some scholars in favor of a certain type of sociology (such as "non-Western sociology") might subjectively expect that this type could replace others, from the point view of sociological development worldwide; however, "Western sociologies" and "non-Western sociologies" are not meant to replace each other but to pluralistically coexist and stimulate each other.

From the above discussion, it is clear that in the formation of "post-Western sociologies," Western and non-Western sociologists will respectively play their different roles. Because "post-Western sociologies" aimed at transcending "Western sociologies" are to be constructed through the historical culture and discourse resources in non-Western societies, non-Western sociologists, who are relatively more familiar with the historical culture and discourse resources in non-Western societies, play a more important role. However, if Western sociologists do not participate in the "post-Western sociologies" constructed by non-Western sociologists, then there might only be some indigenous theories, which would preclude worldwide influence and would fail to have universal meanings and values similar to Western sociologies. Therefore, for "post-Western sociologies" to become theories with universal validity, transcending the non-Western world or view, Western sociologists play a crucial role.

Moreover, the formation and development of "post-Western sociologies" rely on constant mutual learning, communication, and understanding between Western and nonWestern sociologists. On the one hand, for non-Western sociologists, all types of "postWestern sociologies" (including "non-Western sociologies") are not only different from but also transcend "Western sociologies"; hence, learning and understanding of "Western sociologies" become preconditions. On the other hand, for Western sociologists, if they are only familiar with the discourse of Western sociologies and are unaware of the discourse of non-Western sociologies, then they are hardly able to transcend the given view and to construct "post-Western sociologies" transcending "Western sociologies." Therefore, "post-Western sociologies" are to be constructed by neither non-Western sociologists unaware of "Western sociologies" nor Western sociologists unaware of "non-Western sociologies." 


\section{Why use the concept of "post-Western sociologies?"}

Let us move on to another important question: "Why propose and use the concept of 'post-Western sociologies'?" It seems that the several types of "post-Western sociologies" mentioned here are the direct or indirect outcomes of the "indigenizing sociology" movements in non-Western countries (the "post-Western sociologies" in nonWestern countries can be seen as the direct outcomes of the indigenization of the sociologies in these countries. In contrast, the "post-Western sociologies" in the Western world are the imported versions of the former and counted as the indirect results of the indigenization of the non-Western sociologies) and thus can be subsumed under the rubric of "indigenized sociologies" in non-Western countries. Is it then a superfluous endeavor to propose a concept of "post-Western sociologies"?

My answer to this question is no, not at all. In fact, formulating a concept of "postWestern sociologies" would contribute to our more detailed description and profound analysis of the "indigenized sociologies" in non-Western countries. It would further facilitate our appropriate understanding and treatment of the relations between "the West" and "the rest."

What is the "indigenization" of sociology? Scholars have already given diverse answers to this question. However, for a considerable period of time, they basically interpreted it as a process of transforming the sociologies that originated and developed in the Western world to meet the indigenous needs of non-Western countries. It includes translating the original Western sociological notions and propositions into indigenous language, turning their attention from Western societies to non-Western societies for research subjects (more specifically, applying Western sociological concepts, theoretical perspectives, and methodology to their study of the historical and practical issues and phenomena in non-Western, indigenous societies, hiring indigenous scholars to study and teach sociology, illustrating the sociological lectures, textbooks, or other scholarly works with indigenous cases and materials), and amending, supplementing, or innovating the original Western concepts and propositions according to their application in indigenous contexts, to strengthen their capacity to explicate the historical and practical phenomena in non-Western societies and to suit their demands of construction and development. Actually, as elaborated above, the various "indigenized sociologies" based upon such an interpretation are exactly the first two types of "Western sociologies translated into a certain language" and "post-Western sociologies" I discussed in this article.

However, in recent years, a brand-new interpretation of "indigenization" emerged, at least in China, which equates "indigenization" to "de-Westernization" or "nonWesternization" in humanities and social sciences and to the restoration and reconstruction of Chinese traditional scholarship or culture in contemporary China (also called "de-Westernization and re-sinicization;" see $\mathrm{Hu} 2005)$. The sponsors of this kind of "indigenization" (or "sinicization") trend regard the process of Chinese scholars rearranging and reforming the traditional scholarship (such as converting the traditional Chinese studies of the classics into some modern disciplines of Chinese philosophy, history, and literature) as a process of "Westernization" and harshly criticize it. They suggest an introspection of this "Westernization" process in the aspects of disciplinization, systemization, and categorization as well as a restoration or reconstruction of the Chinese traditional culture and scholarship in the current circumstance (for instance, 
through renaming "Ancient Chinese Critical Theories" or "History of Ancient Chinese Literary Criticism" as "Chinese Critical Theories," they attempt to reach a certain consensus: "Only the tradition of ancient Chinese critical theories can represent the subjectivity of the study of Chinese literature and arts" (see Cao and Qiu (2010)). These scholars, "concern more about the reconstruction and revival of the ancient Chinese critical theories in modern China [...] about what parts of ancient Chinese critical theories can not only be connected to the modern but also replace the West," or stress that "rooted in Chinese history and culture, Chinese literary theories are utterly different from those in Western cultures. In the vitally important Qi-Ontology system, for example, "heart" (xin, 心) and "things" ( $w u$, 物), "principle" ( $l i$, 理) and "vital energy" ( $q i$, 气), “the way" (dao, 道) and "instruments" ( $q i$, 器) are not antithetic but different facets of the same object. Chinese critical theories have their very own cultural and ideological foundations, which are not supposed to be abandoned." (Hu 2005). They believe that "If we want to establish a Chinese modern critical theory, the utmost priority is to de-westernize, to rebuild a unique discourse with our own national characteristics and to seek for the Chineseness during our construction of the Chinese modern critical theory, which only exists in the pre-westernized ancient Chinese critical theories. If only we inherit the uncontaminated tradition from the ancient Chinese critical theories, the hybridity and confusion in modern critical theories would be dissipated and the Chineseness spontaneously displays itself. Since the 1990s, the uniqueness of the socalled 'poetic expression' of ancient Chinese critical theories has drawn unprecedented attention in Chinese academia. It has already become a crucial theoretical orientation in the study of ancient Chinese critical theories to disparage contemporary Chinese critical theories while glorifying their ancient counterparts, to intentionally highlight the heterogeneity between Chinese and Western critical theories, and to strenuously advertise the distinctiveness of Chinese ancient critical theories, without taking into consideration its efficiency in the context of the contemporary literature." (Dai 2007).

It seems that the above ideological tendencies of "de-Westernization," "nonWesternization," or even "anti-Westernization" have not had a considerable impact on the realm of sociology for now. However, logically, the core ideas advocated by these trends can be applied to sociological studies, and then lead to the establishment of the "non-Western sociologies" discussed earlier in this article.

What will actually happen if we do apply the theoretical stand of "de-Westernization" or "re-sinicization" to the field of sociology? Most likely, what has already been achieved and developed by Chinese sociologists since the early twentieth century would all be labeled as "Western sociology" or "westernized sociology" and be excluded from Chinese sociologies-because unfortunately, the pure "Chinese sociology" has not been built or rebuilt yet.

Can we accept a conclusion such as this?

Based on my elaboration and analysis of the "sociologies in non-Western countries" in this article, I think this conclusion is difficult to accept, and thus virtually cannot be accepted.

According to the description and analysis I made above, the sociologies formed and developed in a non-Western country, such as China, can at least be classified into four possible types: "object-transformed indigenization," "supplemented-modified-renewed indigenization," "theoretical substitution indigenization," and "theoretical-methodical 
substitution indigenization." Aside from the last one, which falls directly under the rubric of "non-Western sociologies," the other three, more or less, cannot cut off their relations with Western research traditions. However, should we simply repel these three because of their "westernness"? The answer is in the negative. Let me offer a further explanation.

\section{Why use the concept of "post-Western sociologies": dialectics of the relationship between the universal and particular}

The proponents of "de-Westernization" or "re-sinicization" give three reasons to justify their position. First, they indicate that the Western sociologies only reflect and represent the historical experiences of the westerners and are thus inapplicable to nonWestern societies. Second, they hold that the Western sociologies are produced to reveal only the world of meanings (or cultures) of Westerners, so it is irrelevant to the entirely different cultures of non-Western societies. Finally, they believe that "Western sociologies" implicate a sort of discourse power (or hegemony) of Western sociologists over those in the non-Western world. Only an independent "non-Western sociology" would help Chinese sociologists, as well as the sociologists in other non-Western countries, to win an equal opportunity for the academic dialogue. Could these reasons be justified?

Let us first peruse the first reason. The proponents of "de-Westernization" usually believe that, as the systems of knowledge formulated by "Western" sociologists, "Western sociologies" are mainly the summation of the social experiences of Westerners and the representation of the historical courses of the development of Western societies. Because of the distinctions between the Western and non-Western societies, the sociologies originally invented to explain the social and historical phenomena of Western societies cannot be applied to the non-Western societies and are thus doomed to be the "particular," instead of "universal" knowledge. Hence, simply adopting such particular knowledge will lead to a misinterpretation or even distortion of the non-Western social phenomena. For a more accurate, objective understanding and representation of the past and present of the non-Western societies, it is necessary to realize the "indigenousness" and "limitations" of Western sociologies, to stop viewing Western sociologies as "universal knowledge," and to formulate and develop some new sociological knowledge that stands on the firm ground of our intensive study of every particular society, that overcomes the limitations of Western sociologies and that is capable of faithfully representing, profoundly understanding, and precisely interpreting the historical and practical phenomena in non-Western societies. This knowledge is the so-called "nonWestern sociologies."

In my opinion, this is an ambiguous idea that exaggerates the individual uniqueness of both Western and non-Western societies while disregarding their shared features. We cannot deny the fact that, as the crystallization of the social experiences of the West, the "Western sociologies" are "indigenous" knowledge systems. However, does an "indigenous" knowledge system, derived from the life experiences of the residents of a certain region, only reveal and represent the traits of that particular region? Could it not contain some universally applicable contents that go beyond the geographical limitations? I believe the answer is no! It is mainly because, although the subjects of sociologies (i.e., social phenomena) always exist as independent individuals, after being 
represented and encapsulated by sociologists with highly generalized propositions and abstract concepts, the underlying commonalities of these social phenomena are exhibited, transcending the spatial and temporal restrictions.

I would like to briefly demonstrate it with a schematic example. Let us suppose that (1) in "Western society," the social phenomena that have been observed are: A1, A2; B1; C1, C2, C3. (2) In "non-Western society," the social phenomena that have been observed are: A1, A2, A3; B2; 2 ; and $\mathrm{D}^{5}$.

As we have noticed, the observed social phenomena in "Western society" are different from those in "non-Western society". Compared to the "Western society," an additional A-type phenomenon (A3) is observed in "non-Western society;" a completely different B2 replaces B1; C1 and C3 are missing; finally, D1, a new type of phenomenon, is discovered.

According to formal logic, we can obtain a set of notions to describe the various social phenomena in "Western society." For instance, A, B, and C (among them, A is the abstract of the observed particular phenomena $\mathrm{A} 1$ and $\mathrm{A} 2$; $\mathrm{B}$ is the abstract of the individual phenomenon $\mathrm{B} 1$; and $\mathrm{C}$ is the abstract of $\mathrm{C} 1, \mathrm{C} 2$, and $\mathrm{C} 3$.), as well as a set of theoretical propositions that describe and explain the relations of the phenomena are signified by the notions. When these propositions are linked through a certain format, a sociological system SI, which can be employed to describe and interpret the observed phenomenon in Western societies, is established. Now, here is the question: Does a sociological system based on the empirical materials derived from the observation of the social phenomena of "Western society" only apply to those phenomena observed in Western societies, and is it inapplicable to those observed in non-Western societies? My answer is in the negative.

Let us conduct a thought experiment to examine the possible scenarios when applying the above hypothetical Western sociological system SI to non-Western societies. We are likely to see the following:

1. The concept A does well in describing and explaining the phenomena A1 and A2 but likely makes us ignore the existence of the phenomenon A3.

2. It seems that the concept $B$ can be used to describe and explain the phenomenon B2, but one might feel that the description and explanation are not felicitous and cannot utterly match the observation.

3. It is more felicitous to apply the concept $\mathrm{C}$ to the phenomenon $\mathrm{C} 2$.

4. There is no appropriate concept to describe and explain D1.

As indicated above, when applying the Western sociological system SI to nonWestern societies, it is neither fully suitable nor totally unsuitable: it is basically applicable to some phenomena (such as the type $\mathrm{C}$ ), generally applicable to some (such as the type A), roughly inapplicable to some others (such as B), and inadequate for a few types (such as the type D). Therefore, simply concluding that the sociological SI is not applicable to non-Western societies because it is from the West is not appropriate. Furthermore, a slight amendment or modification would improve the applicability of SI

${ }^{5}$ Neither "Western societies" nor "non-Western societies" are an internally homogeneous world and consist of many different "societies." To simplify our discussion, the internal heterogeneity will be temporarily ignored here. 
(such as to formulate a new concept A' by slightly adjusting the connotation and extension of the concept $\mathrm{A}$, to make some essential revision on the concept $\mathrm{B}$ to turn it into a new concept B', to convert the concept $C$ to a new concept $C$, or to add a new concept D) and turn it into a new sociological system SII, which is a sort of indigenously supplemented-modified-renewed sociology as previously discussed and can be more effectively applied to non-Western societies.

In the above example, we presumed that there are many similarities between the phenomena observed in "Western society" and "non-Western society." To highlight the tension, we now presume that the individual phenomena observed in "Western society" and "non-Western society" are completely different:

1. In "Western society," the social phenomena that have been observed are A1, A2; $\mathrm{B} 1$; and $\mathrm{C} 1, \mathrm{C} 2, \mathrm{C} 3$.

2. In "non-Western society," the social phenomena that have been observed are A3, A4; B2, B3; C4; and D1.

Even though the phenomena observed in Western societies seem utterly different from those in the non-Western societies on an empirical level, we cannot arbitrarily conclude that the sociological system SI built from observations in Western societies is entirely inapplicable to non-Western societies. It is because, despite the variations, there are some commonalities between A1, A2 and A3, A4, similarly with B1 and B2, B3, as well as with $\mathrm{C} 1, \mathrm{C} 2, \mathrm{C} 3$, and $\mathrm{C} 4$. What we ought to do is, similar to the situation of the former presumption, to complement and amend the system SI (which means, to formulate a new concept $\mathrm{A}^{\prime}$ by slightly adjusting the connotation and extension of the concept $\mathrm{A}$, to make some essential revision on the concept $B$ to turn it into a new concept $B$ ', to turn the concept $C$ to a new concept $\mathrm{C}$, or to add a new concept $\mathrm{D}$, etc.) to improve its applicability in the nonWestern societies and to convert it into a new sociological system SII that is more universally applicable and would work in both the Western societies and non-Western societies.

Theoretically, there might be nothing in common between the phenomena observed in the Western societies and in the non-Western societies, for instance as follows:

1. In "Western society," the social phenomena that have been observed are A1, A2; B1; and C1, C2, C3.

2. In "non-Western society," the social phenomena that have been observed are D1, D2; E1; and F1, F2, F3.

Therefore, the sociological system SI built upon the empirical observation in the Western societies should be utterly inapplicable to the description and interpretation of the phenomena observed in non-Western societies. To efficiently describe and elucidate the latter, we need to start from scratch to construct a brand-new sociological system on the empirical observation in the non-Western societies. However, this kind of extreme case barely happens in practical life.

Although the discussion above mainly focused on the relations between the sociological concepts and social reality, the basic principles can also be extended to the analysis of the relations between sociological propositions and social realities. 
Thus, obviously, it is untenable to argue that the Western sociologies only apply to the Western societies and are totally impertinent to the non-Western societies because they rest on the empirical materials derived from the observations of "Western society".

\section{Why use the concept of "post-Western sociologies": dialectics of the relationship between insider and outsider perspective}

Let us turn our attention back to the second argument proposed by the proponents of "de-Westernization" or "re-sinicization": Whether the Western sociologies are endowed with "cultural appropriateness" only in the Western societies?

From the perspective of hermeneutical or phenomenological sociology, every social reality is constructed through the meaningful actions of the members of that society. Therefore, to comprehend a certain social reality, it is necessary to penetrate into their world of meanings, taking an "emic" stand ${ }^{6}$ of these actors (instead of an etic stand stressed by positivists), catching the meanings attached by these actors to their own behaviors and the social realities as the consequences through the methods of "understanding" (If the social realities we attempt to explore have been constructed collectively by more than one individual actor, we are supposed to catch the collective meanings attached by all of these actors to their actions and their results. This kind of collective meaning has been assigned different labels, such as "collective consciousness, " "group consciousness," "ethnic culture," "regional culture," "institutional spirit," "ethos," "zeitgeist," and so on.), and revealing the relevance between the significances of the actors' meaningful actions and those of the social realities as the consequences of their actions. In the viewpoint of hermeneutical or phenomenological sociology, only the research findings uncovering the connections between the significances of the actors' meaningful actions and those of the social realities have "significant appropriateness" (or as we occasionally put it-“cultural appropriateness") and only these research findings are counted for the social scientific knowledge with the real power of scientific interpretation. From the perspective of classical hermeneutical or phenomenological sociology, researchers might come to diverse versions of interpretations during the research process, but only one version-the one that most accurately reveals the correlations between the meanings of the actors' actions and their results-is the acceptable research outcome. It can likely be deduced that a sociological doctrine formulated by a scholar who studies Western societies from the stance of hermeneutical or phenomenological sociology only applies to the description and interpretation of Western social realities and is inapplicable to the non-West, even though it precisely uncovers the connections between the significances of westerners' meaningful actions and those of the social realities. To properly describe and interpret the social realities of the nonWestern world, it is necessary to employ the methods of hermeneutical or phenomenological sociology, to start with an "emic" position as members of the non-Western societies, to go deep into the meaningful world of the members of the non-Western societies, and to disclose the relations between the meanings of the members' actions and those of the social realities-only in this way can the non-Western societies be effectively described and interpreted, and only in this way can a sociological doctrine

${ }^{6}$ It is also called the insider's position of the practitioners of a "meaning" or "culture," in contrast to an outsider's position as the observers. 
with the "cultural appropriateness" in the non-Western societies be formulated. Simply applying the concepts and theories that reveal the connections between the meanings of the actions of the westerners and their outcomes to the interpretation of the social realities of the non-Western societies will only lead to a distortion of the latter.

The world of meanings of the actors is constituted with a set of indigenous discourse/semiotic systems (the vocabulary with specific indigenous meanings, narrative approaches with indigenous characteristics, the discourse logic with indigenous essence, and so on). Thus, the so-called "going deep into the world of meanings of the actors," actually means to go deep into the discourse/semiotic system of the actors and to grasp those concepts, narrative modes, and discourse logics that control and restrict the actors' construction of their self-meaning and social world.

This idea makes some sense, in my view, and it is where the significance and value of "non-Western sociologies" are located. Nevertheless, the position of "deWesternization" or "re-sinicization" discussed above is not acceptable. I would like to explain it further here.

First, similar to the situation analyzed above, although the worlds of meanings of the actors in different societies are slightly, or even greatly different, it does not mean that there is not any similarity between them. For instance, there might be vital and indispensable differences between the concept of "God" in the world of meanings of westerners and the concept of "tian" (which can be loosely translated as "heaven") in the world of meanings of the Chinese, between the Westerners' concept of "goodness" and the Chinese concept of "shan" (which can be translated as "goodness"), between "justice" in the west and "renyi" (literally "justice" or "rightness"), between the notion of family in the west and Chinese notion of "jiating" (literally "family"), between the Western concept of "self" and Chinese concepts of "ji,"("self") or "wo" ("I"), etc. Ignoring these differences would cause a misunderstanding of the actions and social realities of westerners or Chinese people. However, it does not mean that there is nothing in common between the above concepts or notions (There probably, not absolutely, is. We need to conduct an empirical investigation, rather than a transcendental prediction, to decide whether there is or not.) Any commonality testified with empirical evidence makes it plausible to apply a certain layer of meaning with generality from one side (the Western concept of "goodness," for example) to the other (such as China).

Furthermore, although embarking from an emic position of non-Western actors and comprehending the non-Western societies through grasping the meaning attached by the non-Western actors to their own actions and the social realities are surely important approaches, or even the prior approach of understanding and interpreting the nonWestern societies, it does not mean that it is the one and only approach. As Geertz elaborates, for those who attempt to understand and interpret (or translate) a world of meanings, an etic stance of an outsider is as valuable as that of an insider. I would like to illustrate it with the following example:

One of my Taoist friends once told me a personal story happened when he was practicing Qigong at home one day. He described that, on that day, he was sitting upright properly at home as usual, according to the Qigong procedure, and soon entered an expected meditation. He found his soul was leaving his body, and heading to a longadmired Taoist palace via a vaguely familiar road. A Taoist priest welcomed him into the palace, in which they had a long conversion. After the conversation, the priest asked 
him to go back home, but he does not know how. The priest told him "return on the same road by which you came." He tried hard to recall the road, and finally remembered it and went back home. He then opened his eyes, and found himself actually sitting at home.

We can derive two different understandings and interpretations regarding this experience: the first one is based on an emic stance. Suppose that the one with such an experience is a devout Taoist, who believes every doctrine taught by his Taoist master; he would interpret this experience in accordance to the Taoist doctrines and is convinced that he just practiced himself into a higher Taoist level and has already obtained the ability to abandon his secular shell to visit his Taoist predecessor. Hence, in the opinion of the supporters of the emic position, while interpreting this experience, we ought to enter his world of meanings and try to understand the experience, as well as his followup actions (such as to practice the Taoist Qigong more frequently, to follow the Taoist doctrines more unswervingly, or to preach the Taoist doctrines more enthusiastically) strictly according to his own explanation. I am not against such a kind of emic interpretation-I completely agree with the idea that we can only understand and even predict the Taoist's experience and actions after acquiring this kind of emic explanation. However, I also think that, aside from this kind of interpretation on the ground of emic points of view, there could be a second kind of interpretation, a sort of interpretation standing on an etic, outsider position. This is exactly the interpretation I attempted to make to my Taoist friend right after I heard his story. My interpretation can be roughly summarized as follows: on that day, you encountered an abnormal mental condition during the Qigong practice. Because you had been cultivating yourself with the Taoist doctrines and standardized Qigong exercises for a long time, those Taoist visions and discourses had penetrated into your subconscious and possessed you to subconsciously experience such a kind of psychological activity. Apparently, this is an interpretation or "translation" based on the modern/Western discourse systems and largely different from the Taoist discourse system. However, who can say this is a pointless interpretation or an understanding that would lead to a misreading of the "authentic" experience of the Taoist? In terms of social, instead of natural sciences, who can make an incontrovertible judgment on which one of the two explanations-the one from the emic stance of the Taoist or the one from my etic standpoint-is a more objective, true, and reliable representation?

Consequently, from the perspective of social sciences, rather than of natural sciences, both the emic and etic interpretations of people's actions and their consequences are meaningful and it is difficult to tell which one of them is more dependable than the other. It also means that, in the case of the interpretation of the non-Western social realities discussed in this article, although the Western sociological perspectives might vary dramatically from the non-Western ones, they are not totally worthless and divorced from the non-Western realities. In fact, for any member of any single society, the understanding of his/her own actions and the social realities should include two perspectives: the insider, "emic" (or "indigenous") perspective, and the outsider "etic" perspective; likewise, for any member of any single society, his/her understanding of an exotic society should also involve these two perspectives: the "emic" perspective of the locals and their own "etic" perspective. As Geertz put it, for one who attempts to understand exotic societies, his/her task is not simply to represent the world of others 
in their own ways of representing them. Instead, he/she needs to display "the logic of their ways of putting them in the locutions of ours; a conception which again brings it rather close to what a critic does to illumine a poem than what an astronomer does to account for a star" (Geertz,[1983]2000:11).

Therefore, it is inappropriate and thus unacceptable to claim that the Western sociologies can only be used to describe and explain the social realities in the West and are not applicable to the non-Western social realities because they only reveal the connections between the meanings of the Westerners' actions and of the social realities and that the non-Western societies can only be represented and interpreted by those doctrines disclosing the relations between the meanings of the actions of the members of the non-Western societies and their social realities. "Non-Western Sociologies" are meaningful for us to understand the non-Western societies, but it is not a proper stance to set them up as an antithesis to the Western sociologies and to use it to reject the latter as well as the doctrines derived from them.

\section{Why use the concept of "post-Western sociologies": on the issue of academic hegemony}

Let us now take a close look at the third argument of the proponents of "deWesternization" or "re-sinicization." Those scholars who support the "deWesternization" in the domain of social sciences believe that the "Western sociologies" were formulated under the guidance of, and thus restricted by, various discourse systems that originated and developed in the Western societies. If Chinese scholars develop a sociology of their own country only through amending, revising, or renovating the existing discourses of the Western sociologies, rather than to make a breakthrough at the fundamental level of the discourse system and to construct a completely different, independent discourse system based on the traditional discourse system of their own country, they can never win their right to speak on an international academic stage. If the sociologists of the non-Western world, such as China, want to obtain the discourse power on that international stage, they need to formulate a pure, dewesternized "Chinese sociology," which is derived from China's own traditional discourse system.

In my opinion, this argument is also untenable.

First, although making a breakthrough on the level of the discourse system and building a pure, completely "non-Westernized" "Chinese sociology" on the traditional discourse system of our own country would help Chinese scholars to win the discourse power from Western sociologists on the international stage, a "de-Westernized," pure "Chinese sociology" is not necessarily an essential prerequisite for dominating an academic conversation. The history, regardless of whether the west or the east, can prove this point to some extent: a passive receiver of a foreign discourse can possibly reverse the situation and become the leader of that discourse world after a period of time, as long as it makes an effort to study and innovate that foreign discourse. For example, Christianity was originally a non-Western discourse system and once fiercely prohibited in a Western society-the Roman Empire. However, it was gradually accepted in the Roman world. Some Roman intellectuals became the authorities of the Christian religion and then gained the discourse power in the Christian world. Similarly, Buddhism was not a Chinese traditional discourse system. Instead, it was an imported foreign 
discourse system, similar to the Western learning we are confronted today. However, after thousands of years of spread and development, Chinese Buddhism has become mainstream and occupies a dominant position in the international Buddhist world today. In the world of Buddhism, the discourse power of Chinese scholars cannot be denied. Therefore, the need to win an academic discourse right per se does not justify the necessity of constructing a completely "non-westernized" "Chinese sociology."

Furthermore, although to make a breakthrough on the level of a discourse system and to build a non-westernized, pure "Chinese sociology" on the traditional discourse system of our own country will help us win the power of academic discourse from Western scholars, obtaining academic discourse power does not necessarily entail the cost of absolute "de-Westernization." In contrast, a pure, absolutely non-westernized "Chinese sociology" would peacefully coexist and/or mutually compete with those sociological systems westernized to various degrees.

Here, we need to answer an important question, what is the relationship between the knowledge of sociology and societies as their targeted subjects. This issue opens two sorts of interpretations: a traditional realistic one and a discourse constructionist one. According to the traditional realistic understanding, sociologies are the direct reflections or representations of the societies they study. Hence, the social worlds that sociologists perceive, contemplate, and address is an absolutely "thing-in-itself" and would not be changed and influenced by any discourse system about that world. In contrast, "sociological studies" are the cognitive processes of reflecting and representing those social worlds, through which we would better accustom ourselves to it, and the socalled sociologies are just the products of those cognitive processes. Although there might be several diverse theories or doctrines successively formulated during the cognitive process of one single social phenomenon, there is only one of them-the one that relatively precisely reflects the research object-that can be accepted and labeled as "truth," while other theories or doctrines with relatively more flaws or errors would be excluded from the ultimate system of the sociological knowledge. In the case of the studies of Chinese society, only the sociological theory or doctrine that relatively accurately reflects or represents the Chinese society will be ultimately accepted as the "truth." In particular, for those traditional realists, there is only one theory or doctrine can be accepted, regardless of whether it is about Western societies or non-Western societies, such as China-that is, what we usually call "monist view of truth."7

In contrast, according to the interpretation of discourse constructionists, sociologies do not directly reflect or represent the social worlds they depict. We can continue describing the relation between sociologies and the social worlds as a reflection or representation but we have to realize that the reflection or representation is only indirect, not direct. Sociologists do not just "reflect" or "represent" social worlds with their blank brain, as claimed by Emile Durkheim and his logical positivist followers. Rather, they "reflect" or "represent" their research subjects under the guidance and restriction of certain discourse systems. Consequently, the sociological theories or doctrines they finally formulate are shaped by, and thus cannot shake off, the regulations of the relevant discourse systems and thus should be seen as a discourse construction conducted by

${ }^{7}$ I would like to clarify that the "traditional realism" I mentioned in this article includes not only the positivism that has been widely criticized but also classical hermeneutics and phenomenology, which I will discuss further in another article. 
the sociologists, led and regulated by that discourse system and targeted at the research subjects. Under the guidance and control of different discourse systems, sociologists might produce different research findings on the same research subject and then form different reflections or representations. There is no dependable approach to judge which one(s) is right and which one(s) is wrong. Therefore, in the eyes of discourse constructionists, there could be diverse theories or doctrines proven to be "correct" in the discourse system they belong to, regardless of whether in Western societies or in non-Western societies such as China. This is what is normally called the "pluralist view of truth."

If we take the position of discourse constructionists, we would be able to realize that the "de-Westernization" in Chinese sociology is not necessarily the prerequisite or price for a pure, "non-westernized" "Chinese sociology." As we discussed and analyzed above, "non-westernized" sociologies are just a sort of "post-westernized" sociologies, and they can peacefully coexist and/or mutually compete with other "post-Western sociologies" still with Western characteristics to different extents. Thus, developing a pure, "nonwesternized" "Chinese sociology" from the discourse system of our own country would help us struggle for the discourse power on the international stage with Western scholars, but it should not necessarily occur at the expense of a complete "deWesternization." Therefore, taking it as a reason to advocate "de-Westernization" or "re-sinicization" is scarcely justified ${ }^{8}$.

Different from the concept of "de-Westernization," the notion of "postWesternization" is more inclusive and realistic: according to the proposition of "deWesternization," in non-Western countries, except for the "non-Western sociologies," other types of sociologies we categorized as "post-Western sociologies" should be rejected as "westernized." Nevertheless, the "post-Westernization" I propose in this article would embrace all of these types of sociologies, including the "non-Western" ones. Compared to the concept of "indigenization," "post-Westernization" has two distinctive features: First, it indicates a different attitude toward the "West." The concept of "indigenization" expresses a tendency to seek for and to maintain the differences from the "West" and would easily, if not necessarily, lead people to a kind of extreme "Western/non-Western" dichotomy. Whereas "post-Westernization" tries hard to avoid that extreme duality and conveys a tendency to keep the continuity, consistency, and commonality while pursuing and maintaining those differences. Second, it expresses an ambition about the "indigenous" sociologies, which differs from that of the concept "indigenization:" since "indigenization" implies a tendency to seek the distinction between the "West" and "non-West," it leads people into a "Western/non-Western" dichotomy and confines the validity of "indigenous" sociologies (including "non-Western sociologies" such as "Chinese sociology") within the "indigenous" domain and thus shadows or denies, intentionally or unintentionally, the universal potential of the "indigenous" sociologies. In fact, even the meanings of the abstract concepts and propositions of those extremely "indigenized" "non-Western sociologies" derived from "indigenous" experiences or discourses would exceed the limit of their place of origin

${ }^{8}$ In the above three sections, I elucidated my objections to the view of "de-westernization" or "re-sinicization" from three perspectives: positive science, hermeneutics, and critical theory. 
and are universally applicable to a certain degree, similar to those of pure "Western sociologies."

Therefore, I propose the concept of "post-Western sociologies" not only because "Western sociologies" might not be applicable to non-Western societies but also because this concept provides us a broader horizon, a more inclusive attitude, and a longer-sighted ambition from the aspect of the theoretical construction of our sociology, multiplies and varies our sociological discourses, and thus paves more paths through which we achieve a better understanding of the social world, and finally contributes to our construction of a brand new social world transcending the Western/ non-Western dichotomy.

\section{Conclusion}

Suppose my explanation of the "post-Western sociologies" above can be accepted: What is their current status of development in the contemporary world-such as in China, a non-Western country, or in France, a Western country? I am not able to provide a precise answer to that question, at least for now. I can only make an approximate estimate based on my previously accumulated impression (my apologies-it might not be quite reliable). In Western countries, "Western sociologies" still occupy a leading position. Although "non-westernized Western sociologies," or even "westernized nonWestern sociologies" have been or are being formulated, they have not achieved enormous influence and prestige. Whereas in a non-Western country, such as China, the one taking a leading role should be the sociologies of "supplemented-modified-renewed indigenization." Sociologies of "object-transformed indigenization" have already become a thing of the past, "theoretical substitution indigenization" sociologies exist but are far from mainstream, and it will likely take a while to see the rise of a pure "non-Western sociology" (i.e., "Chinese sociology" in the case of China). In regard to the studies already launched by the Chinese and French sociologists participating in the projects of "post-Western sociologies" as well as their research findings, which one(s) of them can be classified as "Western sociology"? Which one(s) of them has transcended the sphere of "Western sociologies," heading toward a certain type of "post-Western sociology"? What kind of value or meaning do they have during our collective journey to the "postWestern sociologies?" What sort of contribution can they make in our process of understanding, demarcating, and stepping toward the "post-Western sociologies"? I will leave these questions for further consideration and judgment. This project was titled as "An Exploration of Post-Western Sociologies," which indicates the anticipation of its participants. Will it finally turn out to be a valuable and meaningful work as anticipated? Let us wait and see.

Acknowledgements

N/A

Author's contributions

The authors read and approved the final manuscript.

Funding

N/A

Availability of data and materials 
Competing interests

The author declares that there is no competing interests.

Received: 12 June 2020 Accepted: 25 December 2020

Published online: 28 January 2021

\section{References}

Cao, Shunqing, and Mingfeng Qiu. 2010. A journey of westernization in Chinese critical theory. Journal of Southwest University for Nationalities (Humanities and Social Sciences Edition) (1):229-236.

Dai, Xun. 2007. De-westernization and exploration for Chineseness: The nationalist discourses of Chinese critical theories in the 1990s. Literature and Art Criticism (3):4-10.

Geertz, Clifford. 1983. 2000, Wang, Hailong \& Zhang Jiaxuan (trans.). Local Knowledge: Further Essays in Interpretive Anthropology. Beijing: Central Compilation \& Translation Press.

$\mathrm{Hu}$, Xiaoming. 2005. A rectification of the name of Chinese critical theory: On the trend of De-Westerncentrism in Chinese critical theory study in recent years. Journal of Northwest University (Philosophy and Social Sciences Edition) 35 (5):5-14.

Roulleau-Berger, L. 2011. Désoccidentaliser la sociologie : I'Europe au miroir de la chine. La Tour d'Aigues: I'Aube.

Roulleau-Berger, L. 2015. Post-Western space and doing sociology. Journal of Social Theory 18 (2):237-252.

Roulleau-Berger, L. 2016. Post-Western revolution in sociology. In From China to Europe. Leiden and Boston: Brill Publishers.

Xie, Lizhong. 2012. Post-sociologies: Exploration and reflection. Sociology Study 35 (1):1-26.

Yang, Chunhua. 2012. The fourth path towards the localization of sociology. Theoretic Observation 3:87-88.

Ying, Xing. 2011. Emotions and contentious politics in contemporary rural China. Beijing: Social Sciences Academic Press.

\section{Publisher's Note}

Springer Nature remains neutral with regard to jurisdictional claims in published maps and institutional affiliations.

\section{Submit your manuscript to a SpringerOpen ${ }^{0}$ journal and benefit from:}

- Convenient online submission

$\checkmark$ Rigorous peer review

- Open access: articles freely available online

- High visibility within the field

- Retaining the copyright to your article 